\title{
Magnetic permeability and antiferromagnetism of YBCO superconductors
}

\author{
Y 系酸化物超電導体の透磁率と反強磁性
}

\author{
T. Nose, T. Yamaguchi, M. Yamamoto, K. S h i r a i s hi, \\ T. Sh i ra i s hi, H. Ko i n u m a* \\ Depertment of Communications, Faculity of Engineering, Tokai University \\ 1117 Kitakaname Hiratsuka Kanagawa 259-12 Tel 0463(58)1211 \\ * Research Laboratory of Engineering Materials,Tokyo Instiute of Technology \\ 4259 Nagatsuta Midoriku Yokohama 227 TEL 045(922)1111 \\ (Recieved 25, December 1989) \\ (Accepted 31, May 1990)
}

\begin{abstract}
It is wellknown that $\mathrm{Cu}-\mathrm{O}$ chains indicate superexchange interaction which is the origin of antiferromagnetism. YBCO perovskite has the chains which also originates high-Tc superconductivity. So we focused to the magnetism of superconducting samples at normal conductivity state and cleared the correlation between the antiferromagnetism and the high-Tc superconductivity To investigate the antiferromagnetism, the experiments were carried out by measuring the relative magnetic permeability( $\left.\mu_{\mathrm{s}}\right)$ at $77 \mathrm{~K}$ and room tempreture. The samples which $\mathrm{Cu}$ molar ratio, $\mathrm{X}$ was changed from 2.5 to 3.5 in $\mathrm{YBa} \mathrm{Cu} \mathrm{O}_{7-8}$ were used to study $\mathrm{Cu}$ molar ratio dependence on $\mu_{\mathrm{s}}$ in $\mathrm{Cu}-0$ chains. The samples which pelet forming pressure were varied from 400 to $800 \mathrm{~kg} / \mathrm{cm}^{2}$ were used in this study. Perfect diamagnetism was observed in each sample at $77 \mathrm{~K}$, except sample of $\mathrm{X}=2.5$ which showed a value of about 1 . The samples of $2.8<X<3.5$ indicate antiferromagnetism at room temprature. The antiferromagnetism was the strongest at $X=3.0$ which was most suitable composition for high-Tc superconductors and this sample showed the highest TC end and JC.
\end{abstract}

KEYWORDS: Cu-O chains, superexchange interaction, antiferromagnetism, relative magnetic permeability, $\mathrm{Y}-\mathrm{B}-\mathrm{C}-\mathrm{O}$ superconductor

\section{1. 諸言}

高温酸化物超電導体が発見され（R e f . 1)、 2 年数ヶ月の歳月が過ぎた。この期間に多くの研 究者によって超電導現象機構の解明や実用に向け ての研究が盛んに行われてきた。しかし、残念な がらいまだこの超電導機構に対する基礎的な理解 は確立されていない。その原因は、この酸化物超 電導体のカギである酸素量の制御の問題や、超電 導体を構成する上で狭い最適組成比、そして各成 分元素間で試料製作時、化学反応による組成のず れ等の問題があるためである。

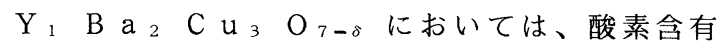
量の多少によって電気的性質は、超電導体から絶 縁体や半導体的に变化する：Pe 一方
磁気的性質は、非超電導体の $7-\delta=6$ で、50 $0 \mathrm{~K}$ 以上に、 $7-\delta=6.15$ では $400 \mathrm{~K} に そ$ れぞれ反強磁性材料の典型的性質の一つであるネー ル温度 $\mathrm{T}_{\mathrm{N}}$ を持つと言う報告がある 3.4 )

して、反強磁性は高温酸化物超電導体構造特有の $\mathrm{C} \mathrm{u}-\mathrm{O}$ 鎖で超交換相互作用により形成されてい ると考えられている5）。これらを詳細に調べた 結果は、超電導体と反強磁性は構造的に隣接し存 在していることを示した6）。

したがって、C u - O 分子が、高温超電導相に重 要な役割を演じている可能性を示唆している。 $\mathrm{Y}$ 系酸化物超電導体において、この 2 つの構造間の 関係をさらに、詳細に調査することは超電導機構 を解明する上で重要であると思われる。本論文で は、超電導を示す試料の常電導状態での反強磁性 
に着目し、この反強磁性状態と超電導特性との相 関性を明らかにした。

\section{2，実験}

本実験では、 $\mathrm{Y} \mathrm{B} \mathrm{a}{ }_{2} \quad \mathrm{Cu}_{3} \mathrm{O}_{7-\delta}$ 系が形成す るペロブスカイト構造において超交換相互作用と 高温超電導現象に重要な役割を演じている C u $\mathrm{O}_{2}$ 構造に注目し、 $\mathrm{Cu}$ の $ル$ 比を欠乏状態から 過剩状態まで変化し常電導状態の反強磁性と超電 導特性との関係を調べた。

試料は、固相反応法により $\mathrm{Y}_{1} \quad \mathrm{~B} \mathrm{a}_{2} \quad \mathrm{Cu} \mathrm{u}_{\mathrm{x}} \mathrm{O}$ 7-s とし、 $\mathrm{x}=2.5 \sim 3.5$ まで変化した。こ れを混合粉末にし、A $12 \mathrm{O}_{3}$ ボート中に入れ仮 焼を酸素雾囲気中、9 $30{ }^{\circ} \mathrm{C} 、 12 \mathrm{~h}$ 行い、次に 本焼成を同様な温度と時間で行った。さらに、粉 末成型をする際に加える圧力や焼成温度を変化さ せることにより結晶成長を制御できることは既に 知られているので（R e f ７７）ペレット成型圧 力を変化して作製された試料においても前述と同 様の実験を行った。この実験は、先と同様に仮焼 を行い、ペレット成型圧力を $400 \mathrm{~kg} / \mathrm{cm}^{2} \sim 80$ $0 \mathrm{~kg} / \mathrm{cm}^{2}$ まで変化させ成型された試料を本焼成し た。以上のように作製された試料を用いて常電導 状態での磁性状態を比透磁率を測定することによっ て観測した。比透磁率の測定回路構成図を F i g .

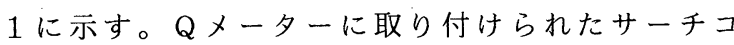
イルに超電導臨界磁場以内の磁場 ( $\mathrm{B}=1.26$ $\left.\times 10^{-2}[\mathrm{G}]\right)$ を卵加し、その中へ試料を入れ た時のインダクタンスの変化により比透磁率を調 べた。この時比透磁率は次式によって与えられる。

$$
\begin{aligned}
& \mu_{\mathrm{s}}=\ell \mathrm{L} / \mu_{0} \lambda \pi \mathrm{r}^{2} \mathrm{~N}^{2}-\text { (1) } \\
& \text { ここで }
\end{aligned}
$$

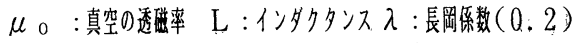

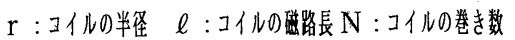

測定は77Kと室温でそれぞれ行った。

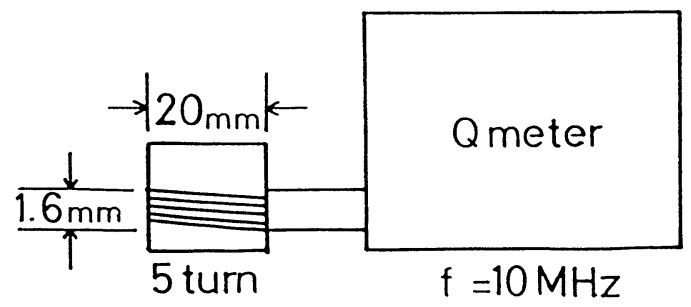

Fig.1 An experimental apparatus of relative magnetic permeability.

\section{3 . 結果及び検討}

$\mathrm{YBa} \mathrm{a}_{2} \mathrm{Cu} \mathrm{O}_{7-\delta}$ において銅のモル比 $\mathrm{x}$ 2. $5 \sim 3.5$ まで変化させたときの試料に対す る比透磁率の結果を F i g . 2 に示す。 $77 \mathrm{~K}$ に おける比透磁率は、 $\mathrm{x}=2.5$ 以外の試料では全 て0であり超電導状態を示した。このように超電 導状態での完全反磁性を本実験の方法によっても 確認でき、この方法で試料の磁性状態を知ること ができる根拠を与える。これに対して、Cuの量 が欠乏した $\mathrm{x}=2.5$ の試料において、常温での 比透磁率は約 1 を与えほぼ常磁性であることを示 す。このようにC uの欠乏した試料では、反強磁 性を示さないことがわかる。 $\mathrm{x}=2.8$ ～ 3 ． 5 では比透磁率 1 以下の值を示し、反強磁性的性質 を示す。また、高温超電導体として最適組成比で ある（Re f． 8 ） $\mathrm{x}=3.0$ で最も強い反強磁 性を示した。さらに、 $\mathrm{x}=2.8 \sim 3.0$ ○と増 加するに従い比透磁率は急激に減少し、 $\mathrm{x}=3$. 0 以上で比透磁率の変化は小さい。このことは、 $\mathrm{Cu}$ の量が 3.0 以下で欠乏している場合、その 量の増加は $\mathrm{C} u-\mathrm{O}$ 鎖の形成への寄与率が非常に 高く、最適值 $X=3.0$ から過剩状態へ増加する にしたがって、Cuを含むぺロブスカイト構造を 持つ結晶密度にあまり変化を与えず、不純物とし て析出されるため $\mathrm{C} u-\mathrm{O}$ 鎖を形成せず透磁率に 大きく寄与しないためと考えられる。以上の結果 は、試料内に形成される高温超電導相が、常温で の反強磁性的性質之非常に強い相関性のあること を示す。そこで、このことをさらに温度一抵抗（ $\mathrm{T}-\mathrm{R}$ ) 特性及びX 線回折特性により調べた。得 られた T - R 特性を F i g . 3 に、そして X 線回 折特性を F i g . 4 に示す。この $\mathrm{T}-\mathrm{R}$ 特性にお いて、常温での抵抗率が、 $\mathrm{x}=3.0$ で最小を示 し、これからず机るに従い抵抗率の増加が観測さ れる。さらに、超電導転移温度（ $\mathrm{T} \mathrm{c}$ オン）は測 定された全ての試料で $93 \mathrm{~K}$ を示したが、 $\mathrm{x}=3$. 0 以外の試料は抵抗がゼロになる温度（Ｔｃゼロ） 付近で裾をひき、 T c ゼロが、低下することを示 す。以上ここで調查した試料での $\mathrm{T}-\mathrm{R}$ 特性の結 果は常温で各試料が示した反強磁性の結果と非常 に良い相関性を再度示した。そして、Fｉｇ．4 に示す $\mathrm{X}$ 線回折特性によっても同様な結果が得ら れた。 $\mathrm{x}=2.5$ の超電導を示さない試料では 2 $\theta=32^{\circ}$ 付近に多くの不純物ピークが観測され、 ペロブスカイト構造の結晶による解折ピークは、 ほとんど観測されなかった。また、 $\mathrm{x}=2.8$ の 試料では $2 \theta=32.8^{\circ}$ の斜方晶ピークは観測 されず正方晶による回折ピークのみが観測され、 
$90 \mathrm{~K}$ 超電導相の結晶成長が不完全であることを 示した。それに対し $\mathrm{x}=3.0$ の試料では、明ら かに斜方晶のピークを示し良好な $90 \mathrm{~K}$ 超電導体 結晶構造を形成していることが分かる。しかし $\mathrm{x}$ $=3.2$ では、斜方晶によるピークの強度が低下 し、正方晶に近い特性を示し、銅が過剩になるに したがって $90 \mathrm{~K}$ 超電導相の成長を妨げ正方晶結 晶成長が、支配的になることがうかがえる。これ らの結果もまたF i g. 2 の反強磁性的性質を示 す比透磁率の結果に良く対応しており、 $\mathrm{T}-\mathrm{R}$ 特 性、X線回折の結果を含め試料の反強磁性的性質 が試料内部の超電導相と密接な関係を持つことを 示す。

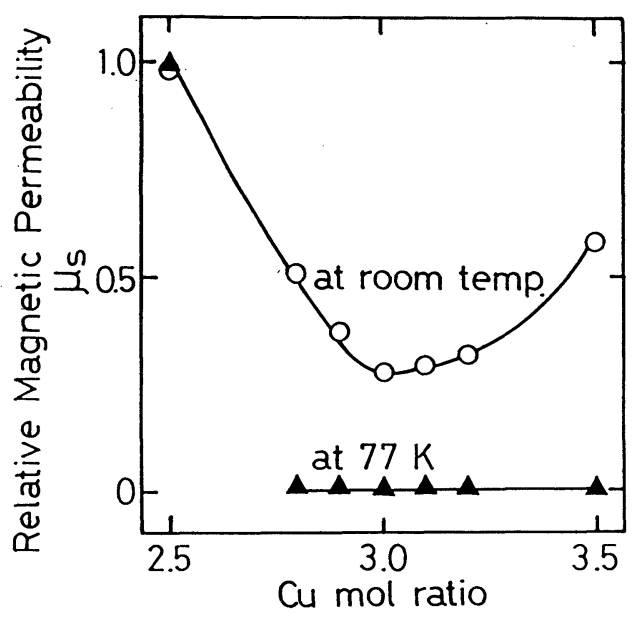

Fig.2 Cu molar ratio dependence of relative magnetic permeability at $77 \mathrm{~K}$ and room temperature.

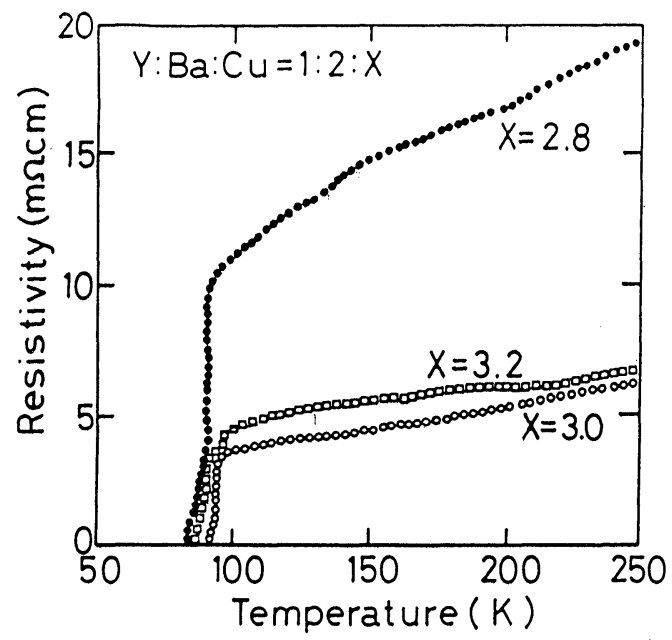

Fig.3 Temperature dependence of resistivity in. $\mathrm{Y} \mathrm{Ba}_{2} \mathrm{Cu}_{\mathrm{x}} \mathrm{O}_{7-\delta}$.

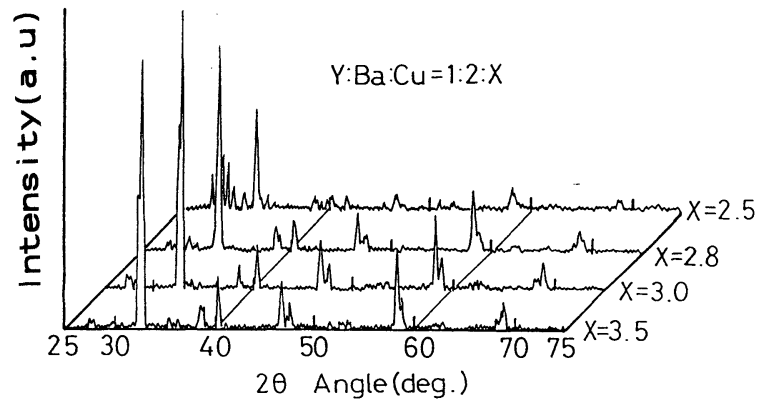

Fig. 4 X ray diffraction patterns at room temperature for $\mathrm{Y} \mathrm{Ba}_{2} \mathrm{Cu}_{\mathrm{x}} \mathrm{O}_{7-\delta}$

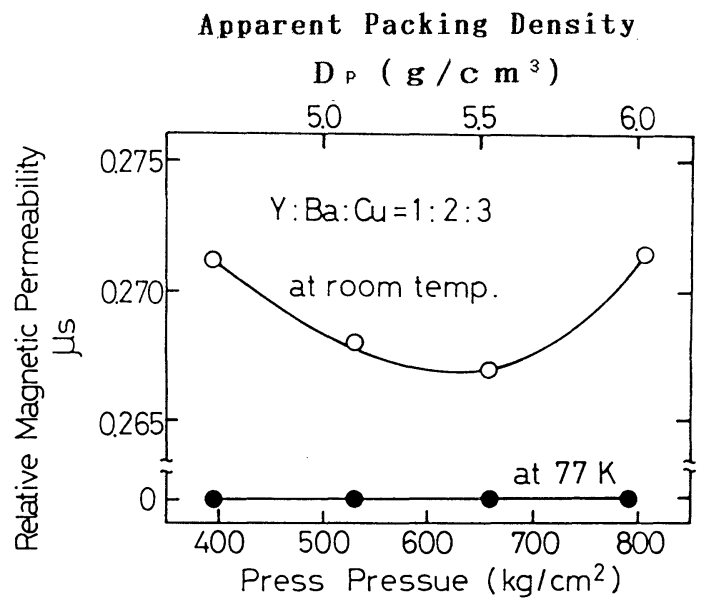

Fig.5 Press pressure and packing density dependence of relative magnetic permeability in $\mathrm{Y} \mathrm{Ba}_{2} \mathrm{Cu}_{3} \mathrm{O}_{7-\delta}$ at $77 \mathrm{~K}$ and room temperature.

また、試料の成型圧力を変えることによって試 料の結晶粒形を变化させ、結果として変化するこ とが予想される試料の密度と反強磁性と超電導性 との関係を調べた。この結果を F i g . 5 に示す。 成型圧力は $400 \mathrm{~kg} / \mathrm{cm}^{2} \sim 800 \mathrm{~kg} / \mathrm{cm}^{2}$ の間で変 化させた。この成型圧力範囲内で作製された試料 の結晶粒を S E M 像により観察した。ここでは紙 面の関係上その結果は省略するが、本実験の範囲 内での成型圧力の変化は結晶粒子の大きさを成長 させることが確認できた。しかし室温における最 も強い反強磁性は成型圧力 $660 \mathrm{~kg} / \mathrm{cm}^{2}$ 付近で観 測され、このとき試料の見かけの充填密度は 5 . $5 \mathrm{~g} / \mathrm{cm}^{3}$ でった。そしてこの試料において最も 高い T c エンドが観測された。このようにこの実 験においても、常温で強い反強磁性を示す試料程 良好な超電導特性を示した。次に、試料の見かけ の充填密度之臨界電流密度の関係を F i g. 6 に 示す。この結果も、最も強い反強磁性を示した見 
かけの充填密度 $5.5 \mathrm{~g} / \mathrm{cm}^{3}$ 付近で最大の臨界電 流密度を示した。

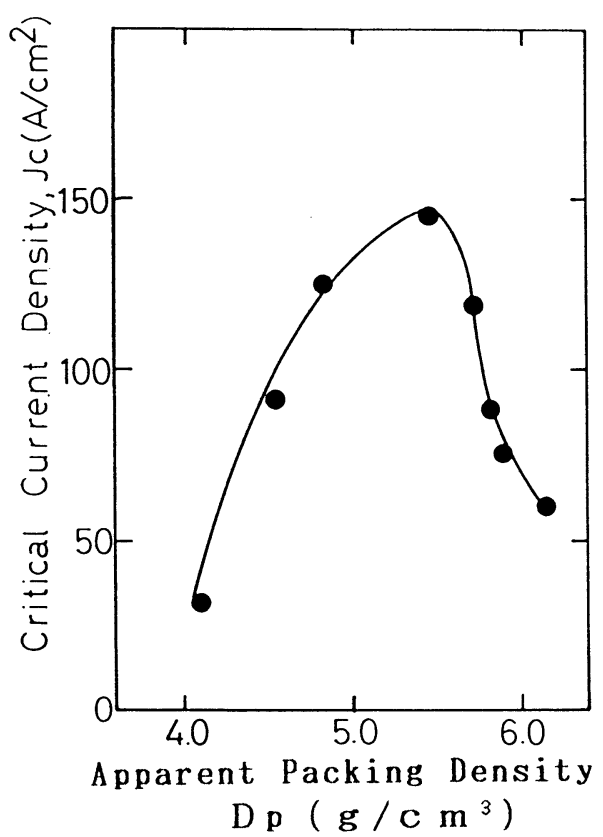

Fig.6 Apparent packing density dependence of critical current density at $77 \mathrm{~K}$.

\section{4. 結言}

$\mathrm{Y}$ 系超電導体のペロブスカイト構造中に形成さ れる C u - O 鎖構造の磁気的性質について調べた。
0-Cu-0構造は、超交換相互作用により常温で反強 磁性を示すことが予想されるが、この超交換相互 作用と超電導現象との相関性を比透磁率という磁 気量を計測することによって調べた。常温におけ る比透磁率の值は、臨界電流密度 $\mathrm{Jc}$, 超電導臨界 温度 Tc、X 線回折特性等の結果から、最も良好な $\mathrm{Y}$ 系高温酸化物超電導体試料では 1 以下の值、つ まり最も強い反強磁性的性質を示した。以上の結 果より、0-Cu-0鎖が形成する電子の超交換相互作 用と高温超電導体との良い相関性が確認できた。

\section{References}

1)BednorZ J. G, and NullerK, A;Z, PysBVo1. 64, NoZ 1986, pp189-193

2) Y. Hasegawa, F. Okamura, A. Ono;CHOUDENDOCERAY ICS, Kougyouchousakai, 1988, pp47-51,

3) Barbara SZPUNAR, V. H. SWITH Jr. andR. W. SWITH ; Physica C152, 1988, pp91-98

4)J. ROSSAT-VIGNODet. al; Physica C152, 1988, pp $19-24$

5)Y. INADA; Journalof PhysicalSocietyofJapanVo 1. 57, No. 9, 1988, pp3128-3140

6)S. K. SINHA, D. Vaknin ; PhysicalRevBVol. 38, No. 4. 1988, pp2477-2485

7) Sudo, Tamura, Nishizawa;RINZORUSOSHIKIGAKU, 1977, NARUZENT. $\mathrm{H}$

8) Yamaka, Tachikawa, Ichinose ; Sankabutuchodendo, Ohm Sha, 1988, pp85-92 